Aim of the study: In the absence of effective therapeutic strategies, cervical carcinoma continues to be second on the list of mortality rates of malignant tumours found in women. We investigated the effects of $\beta$-sitosterol, a natural product isolated from traditional Chinese herbs, on Caski and HeLa cervical carcinoma cells.

Material and methods: Morphological changes were examined by light microscopy. Ultrastructures of Caski and HeLa cells treated with $20 \mu \mathrm{mol} / \mathrm{l} \beta$-sitosterol were documented by scanning electron microscopy and transmission electron microscopy. Changes in mRNA and protein expression were quantified respectively using Real-Time qPCR and western blot methods.

Results: Treatment of Caski and HeLa cells with $\beta$-sitosterol resulted in reduced expression of PCNA, indicative of an inhibitory effect on cell proliferation. This was associated with increased p53 mRNA levels and decreased amounts of HPV E6 transcripts. Expression of p53 and HPV E6 proteins followed a similar trend as that observed for the corresponding transcripts. Caski and HeLa cells treated with $\beta$-sitostero exhibited loss of cell surface microvilli, increased electron density of cell membrane, and decreased organelles.

Conclusions: In conclusion, treatment of Caski and HeLa cells with $\beta$-sitosterol significantly suppressed the expression of genes involved in cell proliferation and oncogenic transformation, while augmenting the expression of genes involved in apoptosis and tumour suppression. Ultrastuctural characterisation of Caski and HeLa cells treated with $\beta$-sitosterol further confirmed the anti-proliferative and anti-cancer activity of this natural product isolated from traditional Chinese herbs.

Key words: $\beta$-sitosterol, apoptosis, Caski, HeLa, HPV E6, p53.

Contemp Oncol (Pozn) 2015; 19 (1): 36-42 DOI: $10.5114 /$ wo. 2015.50011

\section{Effect of $\beta$-sitosterol on the expression of HPV E6 and p53 in cervical carcinoma cells \\ in cervical carcinoma cells}

Dali Cheng, Zhiqiang Guo, Shulan Zhang

Department of Obstetrics and Gynaecology, Shengjing Hospital of China Medical University, Shenyang, China

\section{Introduction}

Cervical carcinoma is one of the most common of all malignant tumours among women. With a five-year survival rate of about $52 \%$, it is second on the list of mortality rates for all malignant tumours found in females. Each year, about 10,000 new cases of cervical carcinoma are reported in developed countries such as the United States, and in China alone 135,000 new cases are registered. Existing therapeutic strategies are ineffective for the treatment of advanced cervical carcinoma. Surgical intervention is effective only when an early diagnosis is made. Conventional methods including radiotherapy and chemotherapy often result in drug resistance and relapse.

Pinellia tuber, a traditional Chinese herb, has been reported to be effective in dissipating tumour mass [1]. 1 In China, cervical carcinoma has been successfully treated with Pinellia alone since the 1970 s. Success rates as high as $70 \%$ have been reported for this method of intervention. Extensive research efforts to uncover its mechanism of action led to the isolation of a colourless crystalline natural product, identified as $\beta$-sitosterol, from Pinellia. Both in vivo and in vitro studies have demonstrated that $\beta$-sitosterol has a protective effect against colon, prostate, cervical, and breast cancers [2-6].

The precise molecular mechanism of action of $\beta$-sitosterol is still unknown. In an effort to develop new therapeutic strategies for the treatment of cervical carcinoma, we sought to identify the molecular mechanisms by which $\beta$-sitosterol suppresses cell proliferation.

\section{Material and methods}

\section{Cell culture}

Human cervical cancer cell lines, Caski and HeLa, were purchased from ATCC, U.S.A. Cells were cultured in RPMI-1640 (GIBCO company) supplemented with $10 \%$ foetal bovine serum (FBS) and maintained in a humidified incubator at $37^{\circ} \mathrm{C}$ and $5 \% \mathrm{CO}_{2}$. Cells were routinely passaged using $0.5 \%$ trypsin. Steadily proliferating cells were used for further experiments.

\section{Immunocytochemistry}

Single-cell suspension of cells in logarithmic growth were separately cultured on coverslips placed inside 24-well plates. The cells were then treated with $\beta$-sitosterol $(20 \mu \mathrm{mol} / \mathrm{l})$ or vehicle for 48 hours. Following this, the medium was removed and the cells were fixed with. Immunocytochemistry experiments were performed using SP kits according to the manufacturer's protocols. After the application of DAB, the intensity of developed colour was quantified and compared.

\section{Scanning and transmission electron microscopy photography}

The Caski and HeLa single-cell suspensions were diluted to $2 \times 10^{4}$ cells $/ \mathrm{ml}$ and plated onto coverslips as described earlier. After 24 hours the cul- 
ture medium was replaced with complete growth containing $20 \mu \mathrm{mol} / \mathrm{l} \beta$-sitosterol or vehicle alone. Culture medium was removed after 24 hours and the cells on coverslips were washed with PBS. Subsequently, the cells were fixed with $1 \%$ osmium tetroxide and washed with PBS. After dehydration and replacement, the samples were put into a sample box and dried for 2 hours in HCP-2 critical point drying apparatus. The dry samples were pasted to the sample table, gold sprayed for 3 minutes in an IB-3 ion sputtering instrument and analysed by electron microscopy and photomicrography. In a separate experiment, Caski and HeLa cells were treated with $20 \mu \mathrm{mol} / \mathrm{l} \beta$-sitosterol or vehicle and were digested for one day to form single cell suspensions. Cells were collected by centrifugation for 15-20 minutes at 2000 rpm. After fixation, dehydration, and embedding, sections of 50-60 nm thickness were prepared using an LKB-I ultra thin microtome, stained with 3\% uranyl acetate (lead citrate), and analysed by electron microscopy.

\section{RT-PCR and Real-Time RT-PCR}

Steadily proliferating Caski and HeLa cells were plated onto culture flasks at a density of $1 \times 10^{5}$ cells $/ \mathrm{ml}$. After 24 hours, adherent cells were treated with $20 \mu \mathrm{mol} / \mathrm{l} \beta$-sitosterol or vehicle for 24 hours, and total RNA was extracted using Trizol reagent.

Typically, $1 \mathrm{ml}$ Trizol reagent was used per flask for cell lysis. To $1 \mathrm{ml}$ of lysate, $200 \mu$ l of chloroform was added and the mixture was shaken vigorously for 15 seconds. The mixture was allowed to stand at room temperature for 15 minutes and centrifuged when the phases separated. The upper organic layer was transferred carefully into fresh tubes, and then $500 \mu \mathrm{l}$ of isopropanol was added, mixed well, and allowed to stand at room temperature for 10 minutes. Following this, the solution was centrifuged and RNA was collected as a pellet after centrifugation. Supernatant was discarded and the pellet was washed twice with $70 \%$ ethanol. The pellet was dried under vacuum and dissolved in $20 \mu \mathrm{LEPC} \mathrm{H}_{2} \mathrm{O}$. The concentration of total RNA in solution was determined indirectly using an ultraviolet spectrophotometer and by quantifying the absorbance at $260 \mathrm{~nm}$. Reverse transcription: typically, $5 \mu \mathrm{g}$ total RNA was reverse transcribed using, oligo dT primers $(0.5 \mu \mathrm{g})$, reverse transcriptase $(15 \mathrm{U})$, dNTP final concentration of $1 \mathrm{mM}$, and RNase inhibitor $(1 \mathrm{U})$. The total volume of the reaction mixture was $20 \mu$ l. The reaction mixture was incubated at $70^{\circ} \mathrm{C}$ for 10 minutes and put on ice. This was followed by adding $4 \mu$ l of $5 \times$ reaction buffer, $2 \mu \mathrm{l}$ of $0.1 \mathrm{M} \mathrm{DTT}$, and $10 \mathrm{mM}$ of dNTP mixture and incubating at $42^{\circ} \mathrm{C}$ for 2 minutes. Reverse transcriptase (Superscript II, $10 \mu \mathrm{M}$ ) was added to the reaction mixture and incubated at $42^{\circ} \mathrm{C}$ for 50 minutes. This was followed by a final incubation at $70^{\circ} \mathrm{C}$ for 10 minutes to end the reaction. The synthesised cDNA was then used a template for further experiments.

For analysis of gene expression in Caski and HeLa cells, GAPDH was used as a standard. The reaction conditions were as follows:

The total volume of each PCR reaction was $50 \mu \mathrm{l}$. A typical reaction consisted of denaturation at $94^{\circ} \mathrm{C}$ for $5 \mathrm{~min}$ - utes followed by 35 cycles of denaturation at $94^{\circ} \mathrm{C}$ for 50 seconds, annealing at $55^{\circ} \mathrm{C}$ for 50 seconds, extension at $72^{\circ} \mathrm{C}$ for 1 minute, and a single final step at $72^{\circ} \mathrm{C}$ for 8 minutes to end the loop. Conditions used for amplification of GAPDH were as follows: denaturation at $94^{\circ} \mathrm{C}$ for 5 minutes followed by 30 cycles of denaturation at $94^{\circ} \mathrm{C}$ for 50 seconds, annealing at $55^{\circ} \mathrm{C}$ for 30 seconds, extension at $72^{\circ} \mathrm{C}$ for 45 seconds, and a single final step of extension at $72^{\circ} \mathrm{C}$ for 8 minutes to end the reaction. The PCR products were subjected to $1 \%$ agarose gel electrophoresis and the gel was stained with $0.5 \mu \mathrm{g} / \mathrm{ml}$ ethidium bromide for visualisation, imaging, and analysis.

\section{Western blot}

Cells in the logarithmic growth phase were plated onto tissue culture flasks at a density of $1 \times 10^{5}$ cells $/ \mathrm{ml}$. After 24 hours, adherent cells were treated with $20 \mu \mathrm{mol} / \mathrm{l} \beta$-sitosterol or vehicle control. The cells were collected after 24 hours, washed with PBS, and lysed. The protein concentration in the cell lysate was estimated using Coomassie brilliant blue. The desired amount of lysate was loaded onto denaturing gels, and the proteins were separated by SDS-PAGE. Separated proteins were transferred into a nitrocellulose membrane. The membrane was blocked with $5 \%$ non-fat dry milk in closed and incubated with primary antibody (1 : 400 dilution), rabbit anti-human $\beta$-actin polyclonal antibody (1:1000). Finally, the membranes were incubated with horseradish peroxidase-labelled goat anti-rabbit IgG, and the target proteins were detected with the help of an enhanced chemiluminescence detection kit ECL.

\section{Statistical analysis of experimental results}

SPSS 10.0 statistical package was used for analysis of variance and test. $P<0.05$ was considered as a significant difference.

\section{Results}

Reduced expression of PCNA following treatment of cells with $\beta$-sitosterol

After treating the cells with $\beta$-sitosterol for 24 hours, we used immunocytochemistry to detect changes in PCNA expression. As shown in Figs. 1 and 2, compared to controls, PCNA expression was significantly lower in Caski and HeLa cells treated with $\beta$-sitosterol for 24 hours $(p<0.05)$.

\section{Structural changes in Caski and HeLa cells following treatment with $\beta$-sitosterol}

Scanning electron microscopy: Vehicle-treated Caski and HeLa cells exhibited a surface rich in microvilli. Treatment of cells with $\beta$-sitosterol for 24 hours resulted in morphological changes reminiscent of those found in nerve cells. Thus we observed significant cell surface microvilli shedding. The cells treated with $\beta$-sitosterol showed a flat morphology and poor three-dimensional sense of difference (Fig. 3).

Transmission electron microscopy: Caski and HeLa cells in the control group under TEM showed an integral membrane. The ultrastructures of the nucleus and organelles were clear. Compared to the vehicle-treated cells, organelle reduction was observed after $\beta$-sitosterol treatment 

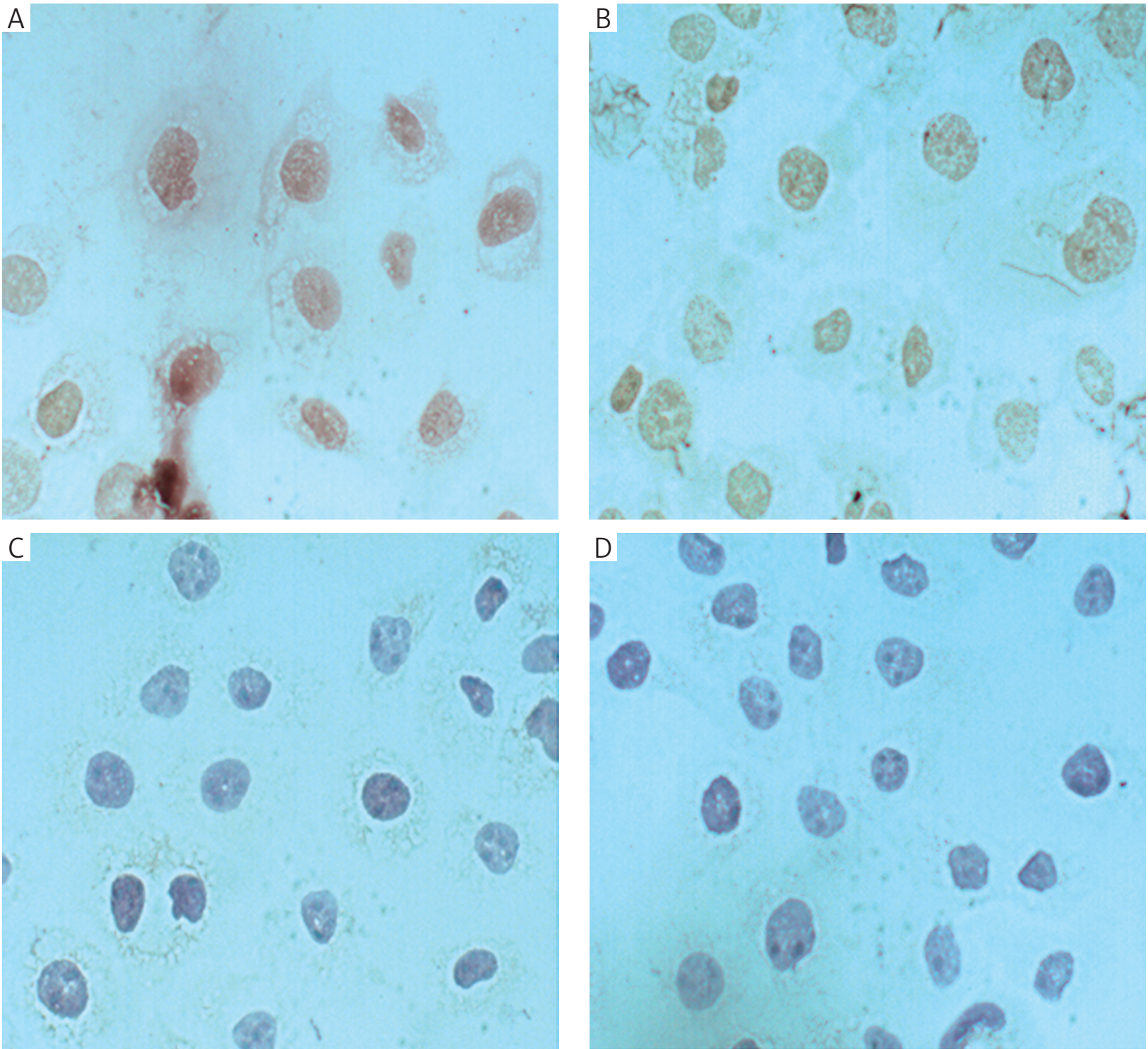

Fig. 1. Changes in PCNA expression after treatment of Caski and HeLa cells with $20 \mu \mathrm{mol} / \mathrm{l} \beta$-sitosterol for 24 hours: A, C) Caski and HeLa cells in control group; B, D) Caski and HeLa cells after treatment with $\beta$-sitosterol

(Fig. 4). Furthermore, the endoplasmic reticulum became loose and fused with cell membrane fusion cells. Cells treated with $\beta$-sitosterol showed the presence of vacuoles, chromatin condensation, and coagulates to mass.

\section{RT-PCR and Real-time RT-PCR}

Conventional RT-PCR results showed that compared to controls, cells treated with $20 \mu \mathrm{mol} / / \mathrm{\beta}$-sitosterol for 24 hours expressed significantly higher amounts of P53 mRNA. Compared to controls, these cells expressed significantly lower amounts of HPV E6 transcripts (Fig. 5).

Real Time qPCR results further confirmed the increased levels of p53 and decreased HPV E6 transcripts in Caski and HeLa cells treated with $\beta$-sitosterol for 24 hours (Table 1 ).

\section{Western blot}

Western blot analysis showed that compared to vehicle treated cells, HeLa and Caski cells treated for 24 hours with $\beta$-sitosterol expressed lower amounts of HPV E6 protein. Additionally, although statistically insignificant, cells treated with $\beta$-sitosterol showed increased p53 protein levels compared to controls (Fig. 6).

\section{Discussion}

The conventional treatment of cervical carcinoma consists of surgery and radiotherapy with optional chemotherapy. There has been limited improvement in the prognosis of patients with cervical carcinoma in the past 20 years. Therefore, new therapeutic methods are critical for lowering the mortality rates and improving the quality of life of patients diagnosed with advanced cervical carcinoma [8, 9]. Additionally, existing interventions, including chemotherapy, present with severe side effects. Botanic sterols have emerged as promising candidates for disease intervention due to their natural origin, minimal side effects, and structural similarity with animal sterols 
$[2,7]$. One of these botanic sterols, $\beta$-sitosterol, found in a variety of herbs, shows structural similarity with cholesterol and has been found to inhibit cholesterol synthesis. A number of studies have shown that $\beta$-sitosterol exhibits anti-tumour activity against breast, prostate, colorectal, and other forms of cancer, promoting apoptosis, bringing about cell cycle arrest, and reducing tumour metastasis.

Here we demonstrate that treatment of cervical carcinoma cells with $\beta$-sitosterol results in reduced expression of PCNA. PCNA was first discovered in the serum of systemic lupus erythematosus and was named by Miyachi et al. in 1978. Several studies found that PCNA regulates DNA synthesis in cells and plays an important role in cell proliferation. Therefore, PCNA is considered as an indicator of cell proliferation. The results of our immunocytochemical analysis show that PCNA expression of Caski and HeLa cells is significantly decreased following treatment with $\beta$-sitosterol. Therefore, we can conclude that $\beta$-sitosterol probably inhibits DNA synthesis in Caski and HeLa cells, thereby suppressing cell proliferation.
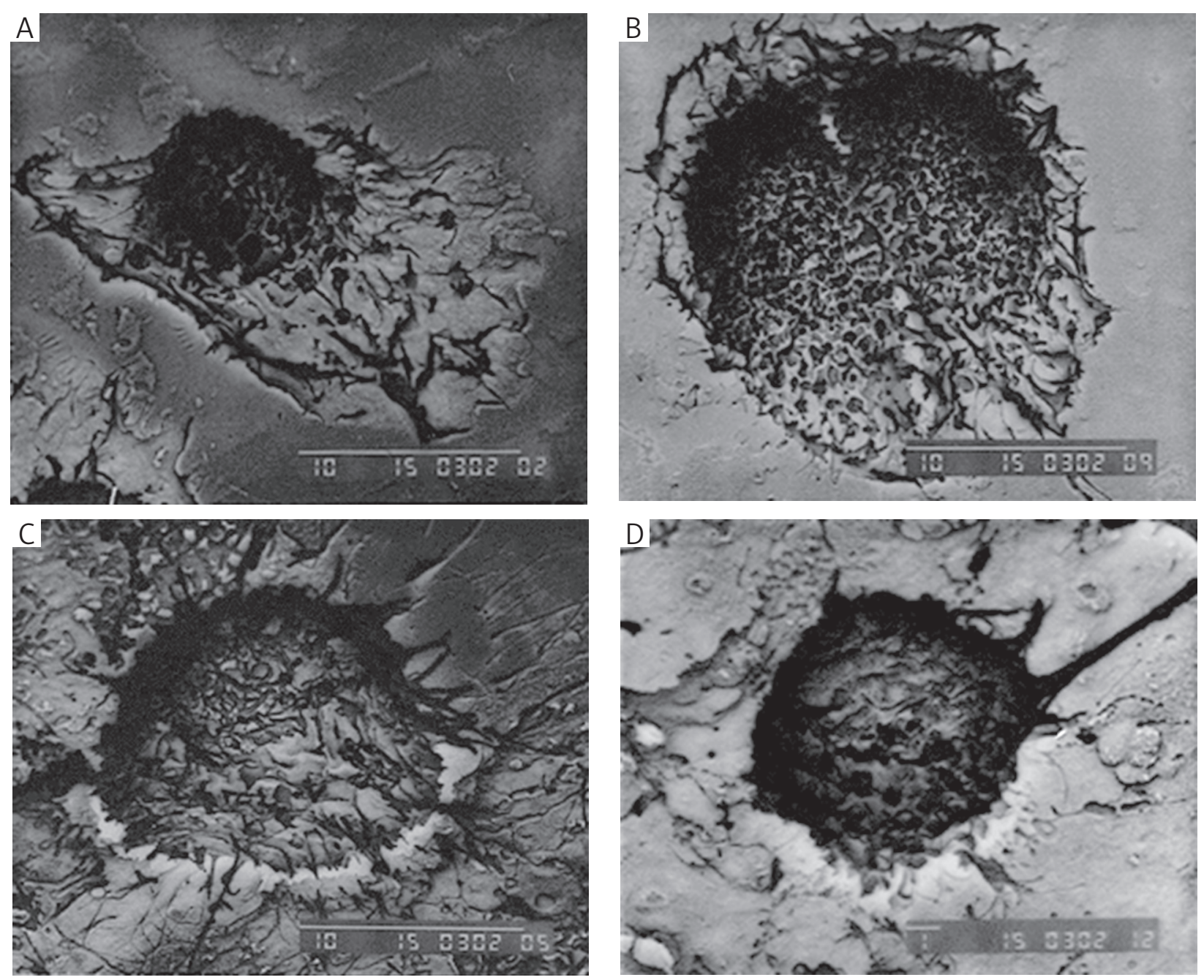

Fig. 3. Caski and HeLa cell surface ultrastructure (X5000) after treatment with $20 \mu \mathrm{mol} / \mathrm{l} \beta$-sitosterol for 24 hours: A, C) control group, Caski and HeLa cells; B, D) $\beta$-sitosterol effects on Caski and HeLa cells

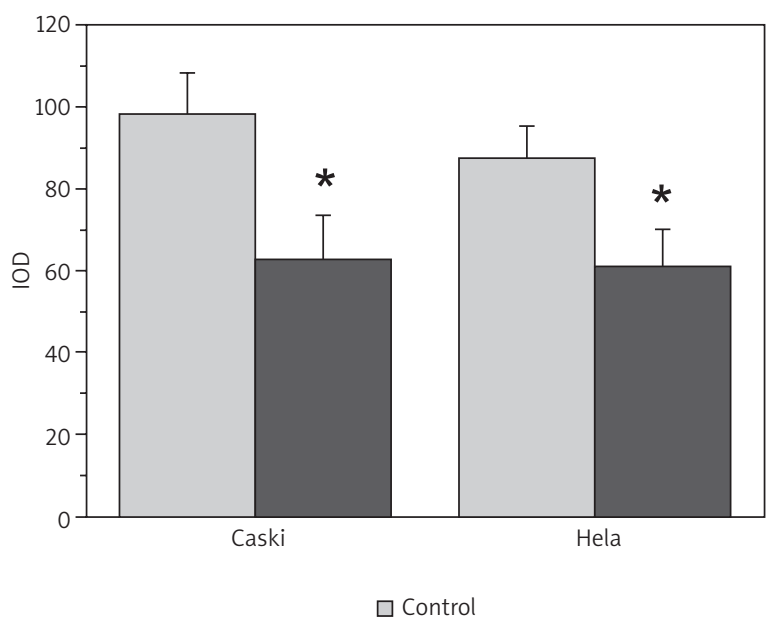

Fig. 2. Integrated optical density (IOD) comparison of PCNA of the Caski and HeLa cells treated with $20 \mu \mathrm{mol} / / \beta$-sitosterol for 24 hours. $P<0.05$ compared with control group 

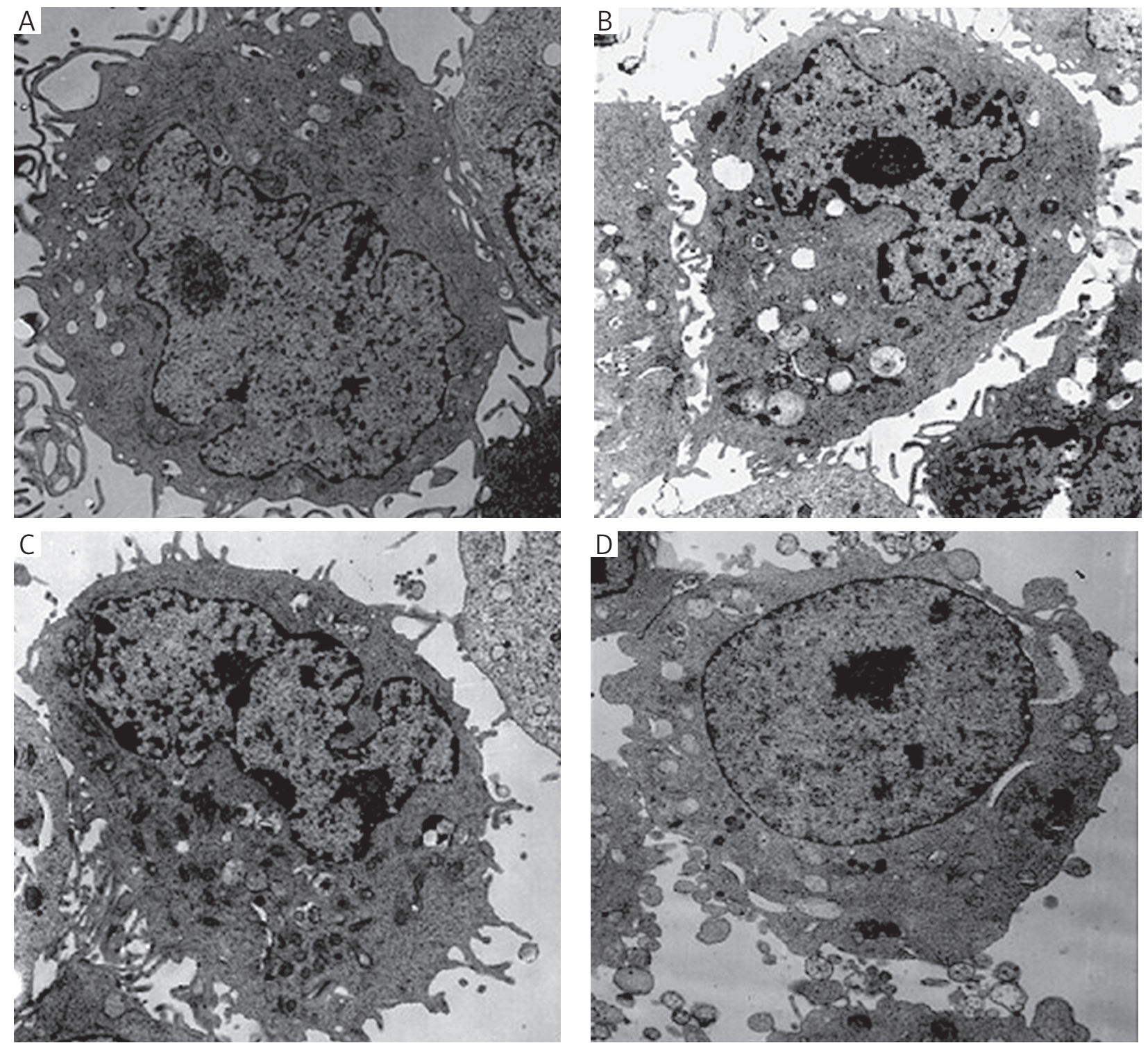

Fig. 4. Ultrastructural changes of Caski and HeLa cells treated with $20 \mu \mathrm{mol} / \mathrm{l} \beta$-sitosterol for 24 hours ( $\times 4000)$ : A, C) control group, Caski and HeLa cells; B, D) $\beta$-sitosterol effects on Caski and HeLa cells)

We also show that $\beta$-sitosterol alters the morphology of Caski and HeLa cells. The results from electron microscopy demonstrate that cells treated with $\beta$-sitosterol have a loss of cell surface microvilli, increased electron density of cell membrane, and decreased organelles. Carcinoma cells possess abundant cell surface microvilli, which increase the cell membrane surface area and meet increased demand for material exchange as well as signal transduction. The overall cellular morphology and ultrastructure of Caski and HeLa cells clearly suggests that these cells gradually lose the characteristics of malignant tumour cells upon treatment with $20 \mu \mathrm{mol} / \mathrm{l}$ of $\beta$-sitosterol.

Cervical carcinoma is a disease of imbalance between cellular proliferation, differentiation, and apoptosis [10]. Apoptosis, a form of cell death, is controlled by a number of genes. In response to exogenous or endogenous apoptotic signals, apoptosis is initiated by activating a cellular suicide program. The precise molecular mechanisms by which apoptosis leads to tumorigenesis and progression is not completely understood. To date, a number of apoptosis-related genes have been identified. Previously, it was reported that $\beta$-sitosterol induces apoptosis in Caski and Hela cervical carcinoma cells. Mutations in the tumour suppressor gene, p53, have been found in several forms of cancers including lung, stomach, and colon. It has been reported that overexpression of 553 plays an important role in the development of cervical intraepithelial neoplasia and cervical squamous cell carcinoma [9]. Numerous reports have also suggested that p53 is an important regulator of apoptosis.

Carcinogenic effects of HPV are caused by the integration of HPV DNA into the host DNA [12-14]. Studies have shown that HPV16 and 18 are able to integrate into host DNA $[13,14]$. Such integration results in the expression of E6, E7, and E2, causing oncogenic transformation [15, 16]. Oncogenes E6 and E7 cause oncogenic transformation by 

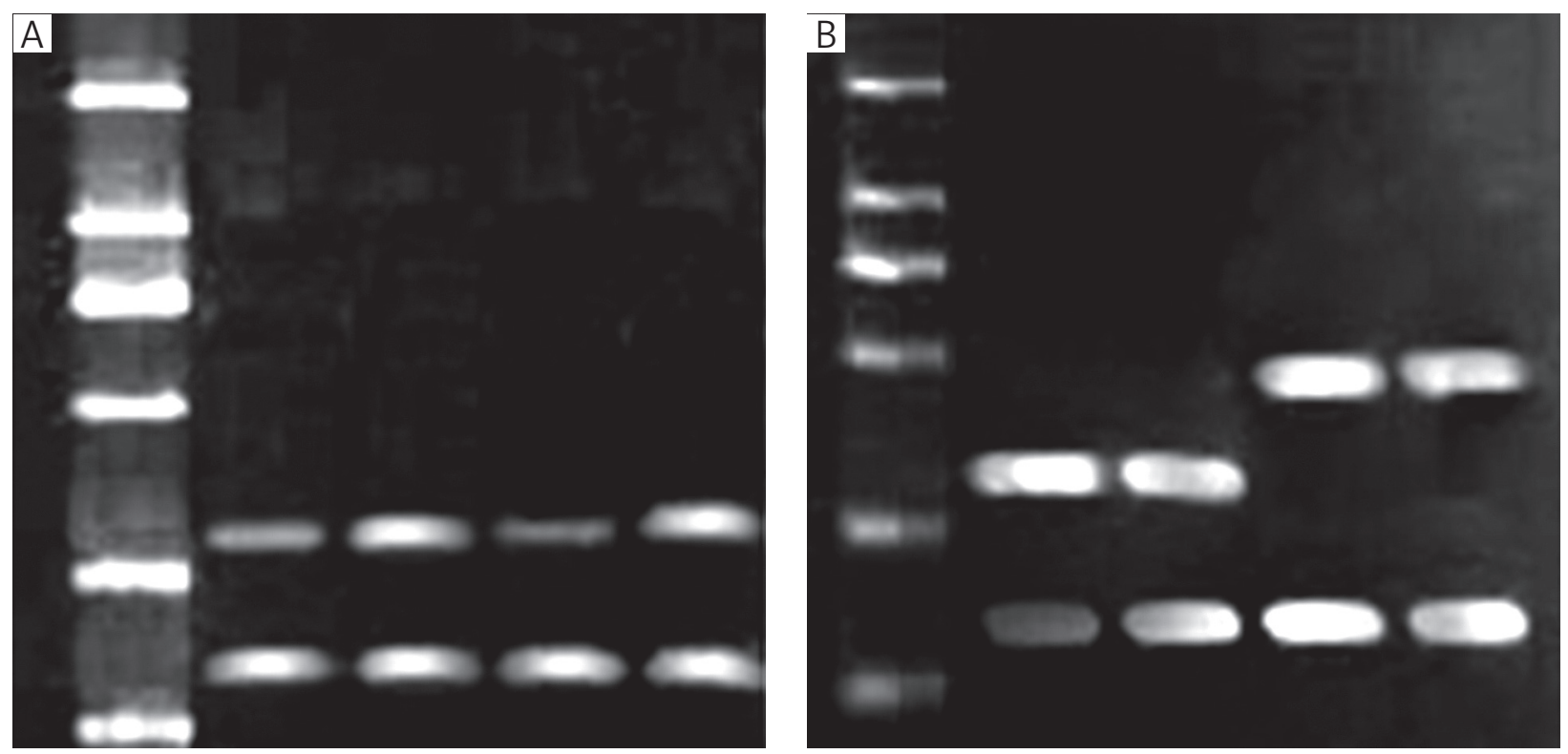

Fig. 5. p53 and HPV E6 mRNA expression in Caski and HeLa cells treated with $20 \mu \mathrm{mol} / \mathrm{l} \beta$-sitosterol for 24 hours

Table 1. OD values (mean $\pm s, n=3$ ) of P53 and HPV E6 mRNA of Caski and HeLa cells after application of $\beta$-sitosterol for 24 hours

\begin{tabular}{lll} 
& P53 mRNA & HPV E6 mRNA \\
\hline Caski & $0.73 \pm 0.12$ & $2.47 \pm 0.54$ \\
Caski + sitosterol & $1.51 \pm 0.45^{\star *}$ & $1.35 \pm 0.27^{\star *}$ \\
Hela & $0.58 \pm 0.09$ & $2.27 \pm 0.72$ \\
Hela + sitosterol & $1.67 \pm 0.52^{\star *}$ & $1.43 \pm 0.31^{\star *}$ \\
\hline
\end{tabular}

Note: Compared with control group, ${ }^{* *} p<0.01$

working closely with regulatory proteins involved in the cell cycle, thereby leading to uncontrolled cell proliferation. Additionally, working closely with ubiquitin protease system, E6 and E7 cause proteolytic degradation of p53 to effectively suppress its tumour suppressor function.

This study analysed the expression levels of apoptosis-related proteins p53 and HPV E6 in Caski and HeLa cells in response to $\beta$-sitosterol. Here we demonstrated that $\beta$-sitosterol significantly attenuates the expression of E6 protein and augments the expression of p53. The effectiveness of $\beta$-sitosterol in lowering the expression of E6 protein points toward its potential antiviral activity.

In conclusion, we demonstrate that $\beta$-sitosterol probably inhibits proliferation of Caski and HeLa cervicle carcinoma cells by reducing the expression of PCNA. The overall cellular morphology and ultrastructure of Caski and HeLa cells clearly suggests that these cells gradually lose the characteristics of malignant tumour cells upon treatment with $20 \mu \mathrm{mol} / \mathrm{l}$ of $\beta$-sitosterol. We also conclude that elevated levels of P53 and reduced levels of HPVE6 viral oncogenes found in Caski and HeLa upon treatment with $\beta$-sitosterol explain its anti-cancer activity against cervical carcinoma.

The authors declare no conflict of interest.
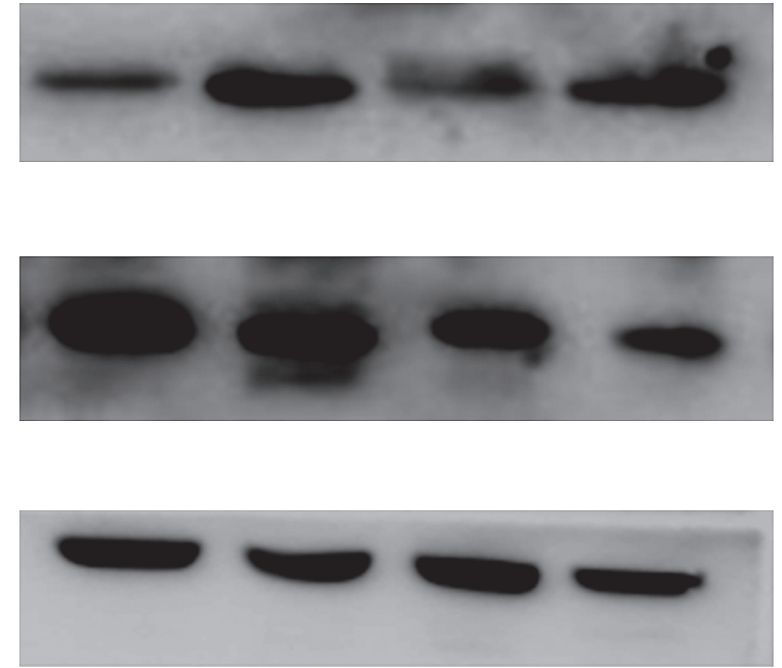

Fig. 6. Changes in p53 and HPV E6 protein expression in Caski and HeLa cells treated with $\beta$-sitosterol for 24 hours

\section{References}

1. Li GL, Jiang W, Xia Q, Chen SH, Ge XR, Gui SQ, Xu CJ. HPV E6 down-regulation and apoptosis induction of human cervical cancer cells by a novel lipid-soluble extract(PE) from Pinellia pedatisecta Schott in vitro. J Ethnopharmacol 2010; 132: 56-64.

2. Choudhary SP, Tran LS Phytosterols: perspectives in human nutrition and clinical therapy. Curr Med Chem 2011; 18: 4557-67.

3. Baskar AA, Ignacimuthu S, Paulraj GM, Al Numair KS. Chemopreventive potential of beta-sitosterol in experimental colon cancer model - an in vitro and in vivo study. BMC Complement Altern Med 2010; 10: 24.

4. Awad AB, Barta SL, Fink CS, Bradford PG. beta-Sitosterol enhances tamoxifen effectiveness on breast cancer cells by affecting ceramide metabolism. Mol Nutr Food Res 2008; 52: 419-26.

5. Jayaprakasha GK, Mandadi KK, Poulose SM, Jadegoud Y, Nagana Gowda GA, Patil BS. Inhibition of colon cancer cell growth and antioxidant activity of bioactive compounds from Poncirus trifoliata (L.) Raf. Bioorg Med Chem 2007; 15: 4923-32. 
6. Jourdain C, Tenca G, Deguercy A, Troplin P, Poelman D. In-vitro effects of polyphenols from cocoa and beta-sitosterol on the growth of human prostate cancer and normal cells. Eur J Cancer Prev 2006; 15: 353-61.

7. Rubis B, Paszel A, Kaczmarek M, Rudzinska M, Jelen H, Rybczynska M. Beneficial or harmful influence of phytosterols on human cells? Br J Nutr 2008; 100: 1183-91.

8. Lasota M, Klein A, Balwierz W. Cytostatic and cytotoxic effects of tyrphostin AG1296 on RMS cells. Contemp Oncol (Pozn) 2012; 16: $1-5$.

9. Kopczyńska E, Makarewicz R. Endoglin - a marker of vascular endothelial cell proliferation in cancer. Contemp Oncol (Pozn) 2012; 16: 68-71.

10. Marquardt K, Buttner HH, Broschewitz U, Barten M, Schneider V. Persistent carcinoma in cervical cancer screening: non-participation is the most significant cause. Acta Cytol 2011; 55: 433-7.

11. Koty PP, Zhang H, Franklin WA, Yousem SA, Landreneau R, Levitt ML. In vivo expression of p53 and $\mathrm{Bcl}-2$ and their role in programmed cell death in premalignant and malignant lung lesions. Lung Cancer 2002; 35: 155-63.

12. Hwang TS, Jeong JK, Park M, Han HS, Choi HK, Park TS. Detection and typing of HPV genotypes in various cervical lesions by HPV oligonucleotide microarray. Gynecol Oncol 2003; 90: 51-6.

13. Ruutu MP, Kulmala SM, Peitsaro P, Syrjänen SM. The performance of the HPV16 real-time PCR integration assay. Clin Biochem 2008; 41: 423-8.

14. Saunier M, Monnier-Benoit S, Mauny F, et al. Analysis of human papillomavirus type 16 (HPV16) DNA load and physical state for identification of HPV16-infected women with high-grade lesions or cervical carcinoma. J Clin Microbiol 2008; 46: 3678-85.

15. Cricca M, Morselli-Labate AM, Venturoli S, et al. Viral DNA load, physical status and E2/E6 ratio as markers to grade HPV16 pos itive women for high-gradecervical lesions. Gynecol Oncol 2007; 106: 549-57.

16. Lukaszuk K, Liss J, Wozniak I, Emerich J, Wojcikowski C. Human papillomavirus type 16 status in cervical carcinoma cell DNA assayed by multiplex PCR. J Clin Microbiol 2003; 41: 608-12.

\section{Address for correspondence}

\section{Shulan Zhang}

Department of Obstetrics and Gynaecology

Shengjing Hospital of China Medical University

Shenyang 110004, China

e-mail: guolichengdali@163.com

Submitted: 27.08 .2013

Accepted: $\quad 16.10 .2013$ 